\title{
A CIRCULARIDADE DO AUTOREFERENCIAL TEÓRICO DO BANCO MUNDIAL EM SUAS PESQUISAS EDUCACIONAIS E SEUS PROJETOS
}

\author{
LA CIRCULARIDAD DEL AUTORREFERENCIAL TEÓRICO DEL BANCO \\ MUNDIAL EN SUS INVESTIGACIONES EDUCACIONALES Y SUS \\ PROYECTOS
}
THE CIRCULARITY OF THE WORLD'S BANK SELF-REFERENTIAL THEORETICAL FRAMEWORK IN ITS EDUCATIONAL RESEARCH AND PROJECTS

\author{
Remo Moreira Brito BASTOS ${ }^{1}$ \\ Antônia Rozimar Machado e ROCHA ${ }^{2}$
}

RESUMO: O artigo trata do paradigma teórico e do modus operandi prevalecentes nos departamentos de pesquisa do Banco Mundial, mormente os afetos à área educacional, esfera em que essa instituição financeira vem se insinuando como organismo central na formulação das novas políticas educacionais globais para os países da periferia capitalista. Pautando-se em fontes bibliográficas e documentais daquela corporação e na literatura acadêmica crítica sobre ela, o estudo conduz a resultados que indicam, ademais do caráter ideológico, a estreiteza de horizonte, a limitação epistemológica e a funcionalidade estratégica à manutenção dos paradigmas neoliberais da pesquisa educacional conduzida naquele banco ou por ele comissionada.

PALAVRAS-CHAVE: Banco Mundial. Pesquisa. Educação.

RESUMEN: El estudio trata del paradigma teórico y del modus operandi prevalecientes en los departamentos de investigación del Banco Mundial, sobre todo aquellos vinculados al área educacional, ámbito en el cual esa institución financiera se insinúa como organismo central en la formulación de nuevas políticas educacionales globales para los países de la periferia capitalista. Con aporte en fuentes bibliográficas y documentales de aquella corporación y en la literatura académica crítica sobre ella, este texto conduce a resultados que apuntan, además del carácter ideológico, la estrechez de horizonte, la limitación epistemológica y la funcionalidad estratégica a la manutención de los paradigmas neoliberales de investigación educacional realizada en aquel banco o por él comisionada.

PALABRAS CLAVE: Banco Mundial. Investigación. Educación.

\footnotetext{
${ }^{1}$ Universidade Federal do Ceará (UFC). Faculdade de Educação. Doutorando em Educação. E-mail: <remomoreira@gmail.com>.

${ }^{2}$ Universidade Federal do Ceará (UFC). Faculdade de Educação Doutora em Educação. E-mail: <r.machado.rocha@bol.com.br>.
} 
ABSTRACT: The article deals with the theoretical framework and the modus operandi prevailing in the World Bank research departments, especially those concerning the educational area, sphere in which this financial institution comes up insinuating itself as a central organism in the formulation of the new global educational policies for the countries of capitalist periphery. Grounding on bibliographical and documentary sources from that corporation and on academic critic literature about it, the study leads to results that indicate, besides its ideological character, the horizon narrowness, the epistemological limitations and the strategic functionality to the maintenance of neoliberal paradigms of educational research conducted at the bank or its commissioned researchers.

KEYWORDS: World Bank. Research. Education.

\section{Introdução}

Projetando-se como o 'Banco do Conhecimento', o Banco Mundial tem em sua área de pesquisa uma instância fundamental em sua estrutura organizacional, porquanto busca, há certo tempo, obstinadamente firmar-se como referência obrigatória na temática do desenvolvimento e, recentemente, da educação, mais especificamente no que concerne a políticas educacionais. Todavia, como ficará claro no decorrer do presente artigo, a despeito da apresentação pelo Banco de seu departamento de pesquisa como independente e pautado por rigorosos e imparciais parâmetros de atuação, sua produção teórica no domínio das políticas educacionais, assim como em outros campos, tem servido de valioso instrumento com vistas à manutenção dos paradigmas caros à perspectiva de mercado, hegemônica naquela instituição financeira.

Uma primeira leitura do documento de planejamento estratégico do Banco Mundial concernente ao setor de Educação, para o decênio 2011-2020, intitulado Learning for all: investing in people's knowledge and skills to promote developmentWorld Bank Group Education Strategy 2020 (WORLD BANK, 2011) - doravante, WBES 2020 -, por mais superficialmente que possa vir a ocorrer, deixa patente a predeterminada lógica neoliberal subjacente à estruturação de todo o documento.

Nesse sentido, não há necessidade de se fazer nenhum esforço para se deparar com prescrições de políticas educacionais funcionais ao mercado, ou com julgamentos depreciativos com relação a modelos públicos de gestão ou de desenvolvimento: o documento está permeado deles - do início ao fim. Na citação a seguir, nota-se o 
entusiasmo do Banco com o êxito da expansão da educação privada em algumas regiões do mundo:

Uma visão mais ampla de oportunidades de aprendizagem inclui serviços de educação oferecidos pelo setor não estatal. Esse setor, que engloba agentes com fins lucrativos e sem fins lucrativos, funciona, alternativamente, como um provedor, financiador e inovador na educação. A prestação não estatal dos serviços de educação em todos os níveis tem aumentado dramaticamente em todo o mundo [...]. Embora muitas vezes se pense que o setor privado atende principalmente aos alunos que podem pagar, as entidades privadas são importantes fornecedoras de serviços de educação até para as comunidades mais pobres, especialmente em áreas em que os governos não chegam. Em muitos países, os governos subsidiam ou contratam organizações não estatais para fornecer educação, mas cobrem grande parte do custo. É essencial, porém, que os governos reconheçam a importância dessas organizações e provejam apropriada regulação e supervisão desses serviços privados, para garantir a eficiência e a coerência da provisão de educação por esses meios. $O$ setor privado também colabora com o governo, tanto para melhorar a pertinência dos serviços de educação como para ampliar o acesso a esses serviços. (WORLD BANK, 2011, p. 19-20, grifos nossos).

Como obstinado promotor da educação privada mundo afora, o Banco Mundial tem sido ferrenho defensor da expansão das mensalidades escolares (taxas de utilização - user fees) desde os anos 1980, em nítida contradição ao básico direito humano de acesso à educação, reconhecido pelo próprio organismo multilateral na primeira frase de seu WBES $2020^{3}$. Com efeito, tem aquela corporação se empenhado com bastante afinco, desde o agravamento da crise estrutural do capital, a partir do início da década de 1970, a fomentar agressivamente a criação de mercados globais para esferas ainda não contaminadas pelo viés mercantil, tais como educação, saúde, previdência social e outras mais.

Como articulador global da economia política de "livre mercado", tal empenho por parte dessa instituição financeira desvela o caráter instrumental de sua atuação no sentido de prover oportunidades de emprego para capitais acumulados, em decorrência da insistente baixa das taxas de lucros obtidas em atividades ligadas à esfera produtiva da economia, sensivelmente agravada com a "crise financeira" de 2008. Contudo, essa "solução" para tal problema de acumulação de capital cria outros problemas com consequências estruturais ainda maiores, como pontua Kamat (2012, p. 43, grifou-se):

3 " O acesso à educação, que é um direito humano fundamental, consagrado na Declaração Universal dos Direitos Humanos e na Convenção das Nações Unidas sobre os Direitos da Criança, também é um investimento estratégico de desenvolvimento" (WORLD BANK, 2011, p. VI, grifou-se). 
A doutrina neoliberal proveu a justificativa ideológica para essas políticas econômicas que enfatizavam os aspectos positivos da 'autorregulação' dos mercados e dos capitais. Mais uma vez, a dialética marxista vem em nosso socorro para mostrar que a 'solução' para o problema da acumulação de capital cria novos problemas adicionais que têm grande alcance e consequências estruturais profundas. $\mathrm{O}$ aumento da polarização social, os níveis gritantes de desenvolvimento desigual dentro e entre países, a natureza volátil dos fluxos de capitais que afundaram economias nacionais inteiras, o desequilíbrio endêmico nas contas nacionais, o aumento da exploração que criou uma elite global de super-ricos, o incremento do número de trabalhadores pobres e a intensificação da crise ecológica são algumas das consequências diretas da globalização e da financeirização do capital.

Supõe-se que essa configuração não seja desconhecida da equipe de pesquisa do Banco Mundial. Não obstante, o fato de restringir suas análises e estudos a fontes internas ${ }^{4}$ compromete irremediavelmente a capacidade daquela equipe de interpretar os projetos, programas e estratégias anteriores do Banco, deixando claro o caráter autorreferencial e a circularidade de sua acrítica e hermética produção teórica. Desvelando sua estreiteza de horizontes, essa metodologia, que busca soluções "de excelência" em horizontes de curto prazo e resultados aferidos de forma inequívoca por restritos instrumentos quantitativos, promove uma sucessão de modismos em políticas educacionais, cada um "rei" por um determinado período, em prejuízo de milhões de crianças e jovens dos países pobres, que têm, assim, obstruído seu direito básico de acesso à educação universal, pública e gratuita de qualidade.

Do ponto de vista epistemológico, o apego excessivo a uma perspectiva teórico-metodológica positivista, mecânica e principalmente economicista na análise do intrincado fenômeno educacional tem limitado sensivelmente o potencial heurístico das pesquisas do Banco Mundial, o que explica os malogros retromencionados da sucessão de insípidos modismos em políticas educacionais, desprovidos de consistência e substância capazes de enfrentar as raízes estruturais das deficiências em aprendizagem existentes nos países periféricos.

Inobstante ao vasto alcance territorial e à heterogeneidade das características das formações econômico-sociais onde atua, a resistência dessa instituição financeira em

\footnotetext{
${ }^{4} \mathrm{~A}$ estreiteza da base referencial sobre a qual se estrutura a pesquisa do Banco é confirmada pela série de entrevistas com antigos membros da equipe do Banco, relatadas por Broad (2006, p. 395), como ilustra a citação que segue: "[...] dentro do Banco, é o conhecimento do Banco que é mais aceito. Como um execonomista do Banco nota em uma entrevista: 'Na medida em que qualquer pessoa da área operacional olha para pesquisa, eles vão olhar para pesquisa do Banco Mundial. Existe um uso muito limitado de investigação independente' (Entrevista em 26 de fevereiro de 2004, reiterando declaração em entrevista de 19 de fevereiro de 2004)".
} 
utilizar outros enfoques, dependendo da natureza da estrutura e do contexto da conjuntura encontrada, impede-lhe a apreensão das relações e dos vínculos entre as variáveis que interagem no complexo sistema educacional. A passagem abaixo, extraída do WBES 2020 (WORLD BANK, 2011, p. VIII, grifou-se), ilustra, possivelmente de maneira até constrangedora, as deficiências do método de abordagem ora exposto:

No nível social, pesquisas recentes mostram que o nível de competências medidas por desempenho em avaliações de estudantes internacionais, como o Programa Internacional de Avaliação de Alunos (Pisa) e o Tendências no Estudo Internacional em Matemática e Ciências (TIMSS), prevê taxas de crescimento econômico muito melhores do que fazem níveis médios de escolaridade. Por exemplo, um aumento de desvio padrão em capacidade de leitura e de desempenho em Matemática (equivalente a uma melhora de aproximadamente $15 \%$ do desempenho do mediano para o topo) é associada com um grande aumento de 2 pontos percentuais do PIB anual de crescimento per capita.

O uso generalizado de testes nacionais e internacionais de avaliação, como o Programa Internacional de Avaliação de Alunos (Pisa, sigla em inglês), o Exame Nacional de Desempenho de Estudantes (Enade), o Exame Nacional do Ensino Médio (Enem), dentre outros, nos últimos anos, como instrumentos destinados a medir a aquisição de habilidades em determinado sistema educativo, oculta a debilidade desses mecanismos para descobrir os meios e as efetivas condições de aprendizagem em diferentes contextos socioculturais e sistemas educacionais.

Elide-se a realidade de que a aprendizagem é um fenômeno humano eminentemente contextualizado, suscetível às condições predominantes nos diversos ambientes e aos inúmeros fatores externos que incidem sobre o processo, os quais os métodos positivistas, apesar de insistirem, não conseguem controlar, em qualquer enfoque sistêmico.

Nesse sentido, Klees, Samoff e Stromquist (2012) pontuam que a atual estratégia de "Aprendizagem para Todos" consiste, na verdade, em uma estratégia "Teste para Todos", baseada na reforma educacional empreendida nos Estados Unidos denominada No Child Left Behind, e que "[...] o que o neoliberalismo tem nos dado na educação, e em outros campos, é uma estandardizada estratégia global de reforma, com base puramente em uma ideologia política, sem levar em conta pontos de vista alternativos e evidências" (KLEES; SAMOFF; STROMQUIST, 2012, p. 228).

Com efeito, esses pesquisadores entendem que, pelo papel que desempenha no sistema institucional interestatal de controle global do capital, dificilmente o Banco 
Mundial teria maiores margens de manobra para praticar políticas educacionais alternativas sem comprometer sua atuação como órgão articulador da compatibilização das estruturas estatais dos países periféricos à dinâmica da acumulação global capitalista.

Assim, compreende-se por que, a despeito do calibre de seu autoexaltado setor de pesquisas, a instituição possui vexatório histórico de fracassos em experimentos educacionais nas últimas décadas em inúmeros países subdesenvolvidos onde opera: o Banco simplesmente não pode abrir mão da adoção da teoria do capital humano como paradigma teórico-metodológico, por mais frágil que esta tenha se mostrado nas últimas décadas, pelos motivos que serão esclarecidos adiante.

Desde seus primeiros documentos de políticas educacionais, o Banco Mundial utiliza essa teoria para justificar não somente $o$ seu envolvimento com a educação, mas também o próprio investimento em si, do ponto de vista do retorno econômico, na educação.

Os primeiros documentos de política educacional do Banco Mundial usam a teoria do capital humano para justificar o investimento em educação (e, concomitantemente, a participação do Banco na educação), enquanto o 2020 usa uma versão revisada dessa teoria concebida pelo atual paladino educacional daquela instituição, Eric A. Hanushek, substituindo o conceito de 'anos de estudo' por 'desempenho escolar' como variável independente para o crescimento econômico. (HANUSHEK; WOESSMANN, 2008 apud VERGER; BONAL, 2011, p. 916).

Recuperando-se brevemente os fundamentos basilares daquela teoria, em sua versão original tem-se que a renda individual é determinada por dois fatores: trabalho físico e educação (investimento humano), a qual se forma pelo investimento em escolaridade e treinamento. Assim, em função do tempo e do tipo de educação, do rendimento escolar, variará a qualidade do capital humano "formado" e, consequentemente, os retornos futuros que este é capaz de produzir.

A teoria, entretanto, esquece um "pequeno detalhe": quem e/ou o que determina as condições sob as quais o indivíduo buscará a "formação" de seu capital humano? Note-se a circularidade da teoria: como não pode referir-se às desigualdades sociais, ela prega que o indivíduo, para possuir as condições socioeconômicas que lhe possibilitem o acesso à educação, tem que investir nesta. Ora, perceba-se que o que era determinante transforma-se em determinado: o sujeito deve educar-se para ter acesso a uma melhor renda, mas para educar-se precisa de fatores socioeconômicos (background) que 
somente uma família minimamente estruturada em termos de renda pode lhe proporcionar. Em uma representação esquemática, ter-se-ia:

$\mathrm{Y}=$ renda; ascensão social, etc.;

$\mathrm{A}=$ acesso à escola; desempenho ou rendimento escolar, etc.;

$\mathrm{B}=$ background socioeconômico;

$\mathbf{Y}=\mathbf{f}(\mathbf{A})$, mas $A=\mathbf{f}(\mathbf{B})$.

Dessa forma, fica nítida a fragilidade dos fundamentos do referencial teórico-metodológico utilizado pelo Banco Mundial em suas pesquisas na área educacional, do qual, não obstante, não pode a instituição afastar-se, sob pena de colocar em risco os pressupostos de sua própria atuação naquela esfera, como articulador institucional global da macroestrutura de poder oligopólico contemporânea ${ }^{5}$.

Ficam nítidos, portanto, o caráter ideológico, a estreiteza de horizonte, a limitação epistemológica e a funcionalidade estratégica à manutenção dos paradigmas neoliberais que presidem o desenvolvimento das pesquisas sobre educação no Banco Mundial, sejam internamente concebidas, por seu departamento, ou externamente, por empresas de consultoria ou mesmo por profissionais autônomos, ad hoc.

\section{O papel institucional do Banco Mundial como articulador da integração dos países periféricos à economia política global}

A análise do WBES 2020 leva à constatação de que, apesar da retórica do documento, o direito à educação não subjaz à nova estratégia do Banco Mundial para a área. $\mathrm{O}$ enfoque instrumental, parcial e pragmatista que aquela instituição financeira imprime à pesquisa e à formulação de políticas educacionais, fortemente influenciado pela doutrina do capital humano, constitui óbice estrutural a uma real perspectiva de desenvolvimento de políticas de fomento ao provimento equitativo de educação de qualidade às populações dos países da periferia do capitalismo.

Ciente do risco de se incorrer em reducionismo, ao se procurar enquadrar a atuação daquela organização multilateral como necessariamente presa à lógica inerente de uma instituição financeira, não se pode, todavia, à luz do construto teórico-factual

${ }^{5}$ Para aprofundamento sobre como a estrutura do departamento de pesquisa do Banco Mundial conduz a produção de pesquisa acomodatícia e mantenedora dos paradigmas neoliberais e impeditiva da emergência de modelos alternativos, reportar-se a Broad (2006). 
que se delineou no presente texto, deixar de concluir que essa, como um banco, dificilmente poderia trabalhar com a premissa da educação como um direito, porquanto essa perspectiva entraria em contradição com todo o arcabouço ideológico que permeia o funcionamento e a legitimação do sistema de dominação imperialista global, ao qual serve o Banco Mundial, calcado na imposição do "livre mercado" e da lógica mercantil para a regulação de todas as esferas da vida humana. Respeitar o direito básico de educação para todo ser humano minaria a emergência e o crescimento de um colossal mercado educacional que hoje movimenta bilhões de dólares, em detrimento do acesso e da qualidade da educação para a população daqueles países. Klees (2012, p. 51) se posiciona no mesmo sentido:

Fundamentalmente, o Banco Mundial é um banco e não sabe o que fazer com uma atuação baseada em direitos. Tudo para o Banco Mundial é instrumental em termos de como isso afeta o crescimento econômico. E um problema básico para o Banco Mundial é que uma abordagem baseada nos direitos não para no direito à educação. E sobre o direito à saúde? À alimentação? À habitação? A uma vida sustentável? Ao próprio desenvolvimento? Tal perspectiva sobre o desenvolvimento contradiz a lógica econômica de um banco e pede mais intervenção do governo do que um neoliberal pode tolerar. Não é de admirar que o Banco Mundial se recuse a ser sério sobre direitos humanos.

Atendo-se ao teor do WBES 2020, Siqueira (2012) corrobora o quadro acima delineado e aponta cinco características que confirmam sua tese de que o referido documento não passa de uma versão requentada dos anteriores, pós-Consenso de Washington: a) eleger a educação como a panaceia para resolver todos os problemas do mundo (econômicos, ambientais, nutricionais, de desenvolvimento, conflitos locais e regionais, guerras, etc. $)^{6}$; b) promover uma visão reducionista da educação, limitada à aquisição de habilidades funcionais à atuação no mercado de trabalho, desvalorizando a experiência de comunidades sem educação formal, notadamente nos países pobres; c) utilizar uma recorrente e descontextualizada perspectiva a-histórica, que despreza relevantes experiências anteriores em educação nos países onde atua, e mesmo suas próprias recomendações precedentes e suas consequências; d) usar como fundamentação para suas políticas educacionais apenas pesquisas conduzidas

\footnotetext{
${ }^{6}$ Atente-se para o imperativo ideológico funcional dessa designação da educação como o remédio para todos os males da sociedade capitalista neoliberal: impedido de reportar-se aos fundamentos estruturais das contradições que marcam a sociabilidade estranhada hegemonizada pelo capital, há que se indicar algum "culpado" por aquelas "externalidades" (ou "falhas de mercados") e se trabalhar na superação dessas imperfeições, contudo sempre dentro dos marcos do sistema sociometabólico prevalecente.
} 
internamente ou por pesquisadores que, mesmo lotados em outras instituições, apoiem sua filosofia de atuação; e e) reforçar um fortíssimo bias pró-mercado.

Difícil não concluir que a perspectiva privatista que o Banco Mundial imprime à educação cumpre uma função crucial no encaminhamento de uma questão vital para a reprodução do capital global: a inexorável necessidade que este tem de buscar indefinidamente alternativas de valorização, tendo em vista a imanente queda na taxa média de lucro na esfera produtiva tradicional. Nesse sentido, a educação, como uma vastíssima e próspera área de reprodução e acumulação de capital, desempenha papel fundamental, notadamente no processo de deslocamento das contradições do mercado capitalista de produção, até onde for, geográfica e temporalmente, possível.

Numa concepção mais ampla, há que se apreender a difícil compatibilização do mandato do qual foi investida aquela instituição multilateral, de indutora do desenvolvimento e do combate à pobreza nos países periféricos, com seu papel estrutural como articuladora da integração desses países à economia política global. Essa tênue e frágil conciliação de interesses tão díspares e antagônicos talvez jogue alguma luz na exclamação de Samoff (2012, p. 118), que questiona:

Como, então, uma instituição que emprega direta e indiretamente uma grande quantidade de especialistas em educação, que possui, pelas suas próprias contas, mais de mil publicações na área, não obstante sua retórica e seu entusiasmo, oferece um modelo de aprendizagem tão estreito e limitado, nada tem a dizer sobre igualdade e como se obtê-la, e se propõe a deixar intacto um modelo de escolarização estruturalmente incapaz de prover educação de massa?

A tese de Samoff (2012), corroborada por este pesquisador, é a de que o Banco Mundial incumbe-se de manipular os países aos quais "assiste", e não de empoderá-los. Dessa forma, enquanto usa termos como "empoderamento", sua maior preocupação, na verdade, é apoiar sistemas educacionais que: preparem trabalhadores para as necessidades de mão de obra da economia política global; sejam entusiasticamente receptivos a investidores locais e estrangeiros; e desencorajem o ativismo, intimidando os cidadãos para que não participem de movimentos de militância democrática. Nesse sentido, da mesma forma que os governos nacionais, o Banco mostra-se apreensivo com os possíveis desdobramentos políticos de uma população mais educada e, por isso, frequentemente se alia a esses governos para conter o ativismo nas instituições educacionais que financia. 
De fato, fica difícil não perceber os imperativos estruturais e institucionais que condicionam a atuação daquela organização financeira internacional. Abrir mão de impor suas soluções de "melhores práticas", forjadas em seus herméticos departamentos de pesquisa e/ou seletivamente pinçadas de experiências-pilotos conduzidas em países pobres, para trabalhar lado a lado com pesquisadores do Terceiro Mundo, que efetivamente conhecem as necessidades $\mathrm{e}$ as peculiaridades de seus sistemas educacionais, comprometeria seriamente o poder daquela instituição financeira global, em duas frentes.

Primeiro, desistir de ou mesmo compartilhar o controle sobre a especificação dos métodos de pesquisa educacional aceitáveis poderia colocar em risco a gestão do modo como a educação e o desenvolvimento são estruturados nos países pobres. A repetência, por exemplo, pode ser entendida, em algumas circunstâncias, como uma medida educacional salutar, em vez de duramente criticada como ineficiência. Análise de taxa de retorno pode ser um parâmetro descartado como incalculável, impertinente e irrelevante. Avaliações internacionais (como o Pisa, por exemplo) poderiam ser desmistificadas como estratégias para imposição e internalização de noções particulares de conhecimento e aprendizagem, que reproduzem e acentuam as desigualdades e as iníquas estruturas de poder naqueles países.

Em segundo lugar, abrir mão de seu autorreferencial teórico-metodológico para confiar mais receptivamente em instituições de pesquisa de países do Terceiro Mundo poderia colocar em risco a capacidade do Banco Mundial para cumprir o seu papel estrutural de gestor da integração dos países pobres à economia política global. Pesquisas desenvolvidas nesses países poderiam desvelar que as recomendações daquela instituição não se adéquam às efetivas necessidades e à realidade econômica e cultural daquelas formações sociais e, por isso, serem descartadas, em vez de aceitas como a verdade inquestionável provinda do oráculo (SAMOFF, 2012).

Conforme assevera esse autor, a incapacidade do Banco Mundial em apoiar o desenvolvimento da pesquisa no Terceiro Mundo não é apenas uma flagrante falha em uma estratégia globalmente propagandeada (Aprendizagem para Todos - 2011-2020), mas fundamentalmente, embora poucos percebam, um requisito para a conservação de seu papel na macroestrutura de poder global institucional. 


\section{Considerações finais}

Dentre os aportes que o presente trabalho pretende trazer para o debate acadêmico em torno do modelo educacional propugnado pelo Banco Mundial para a periferia capitalista, seria pouco provável não se chegar à conclusiva avaliação do imperativo da substituição desse aparelho de controle instrumentalizado pela macroestrutura de poder oligopólico global, como instituição responsável pela formulação de políticas educacionais aplicáveis aos países periféricos, por organizações ou instâncias deliberativas e decisórias alternativas, que reflitam a diversidade política, ética e cultural daqueles países e pugnem por seus soberanos interesses, subordinando as injunções mercantis em uma área vital para o desenvolvimento socioeconômico dessas formações sociais.

\section{REFERÊNCIAS}

BROAD, R. Research, knowledge, and the art of "paradigm maintenance": The World Bank's Development Economics Vice-Presidency (DEC). Review of International Political Economy, London, v. 13, n. 3, p. 387-419, 2006.

KAMAT, S. The poverty of theory. The World Bank's Systems approach to education policy. In: KLEES, S. J.; SAMOFF, J.; STROMQUIST, N. P. (Ed.). The World Bank and Education: critiques and alternatives. Rotterdam: Sense, 2012. p. 33-47.

KLEES, S. J. World Bank and education: ideological premises and ideological conclusions. In: KLEES, S. J.; SAMOFF, J.; STROMQUIST, N. P. (Ed.). The World Bank and Education: critiques and alternatives. Rotterdam: Sense, 2012. p. 49-65.

KLEES, S. J.; SAMOFF, J.; STROMQUIST, N. P. (Ed.). The World Bank and Education: critiques and alternatives. Rotterdam: Sense, 2012.

SAMOFF, J. More of the same will not do. Learning without learning in the World Bank's 2020 education strategy. In: KLEES, S. J.; SAMOFF, J.; STROMQUIST, N. P. (Ed.). The World Bank and Education: critiques and alternatives. Rotterdam: Sense, 2012. p. 109-121.

SIQUEIRA, A. C. The 2020 World Bank education strategy: nothing new, or the same old gospel. In: KLEES, S. J.; SAMOFF, J.; STROMQUIST, N. P. (Ed.). The World Bank and Education: critiques and alternatives. Rotterdam: Sense, 2012. p. 69-81. 
VERGER, A.; BONAL, X. La estrategia educativa 2020 o las limitaciones del Banco Mundial para promover el aprendizaje para todos. Educação \& Sociedade, Campinas, n. 32, p. 911-932, 2011.

WORLD BANK. Learning for all: investing in people's knowledge and skills to promote development. Education Sector Strategy 2020. Washington, DC: World Bank, 2011.

\section{Como citar este artigo:}

BASTOS, Remo Moreira Brito.; ROCHA, Antonia Rozimar Machado e. A circularidade do autoreferencial teórico do banco mundial em suas pesquisas educacionais e seus projetos. Revista on line de Política e Gestão Educacional, Araraquara, v.21, n.2, p. 322-333, maio/ago. 2017. Disponível em: <http://dx.doi.org/10.22633/rpge.v21.n.2.2017.9965>. ISSN: 1519-9029.

Submetido em: 10/06/2017

Aprovado em: 26/07/2017 